\title{
Regional multi-compartment ecological risk assessment: Establishing cadmium pollution risk in the northern Bohai Rim, China
}

\author{
Yajuan Shi ${ }^{a}$, Ruoshi Wang a,b , Yonglong Lu ${ }^{\text {a,* }}$, Shuai Song a , Andrew C. Johnson ${ }^{\text {, }}$, \\ Andrew Sweetman ${ }^{c, d}$, Kevin Jones ${ }^{\text {d }}$ \\ a State Key Laboratory of Urban and Regional Ecology, Research Center for Eco-Environmental Sciences, Chinese Academy of Sciences, Beijing 100085, China \\ b University of Chinese Academy of Sciences, Beijing 100049, China \\ c Centre for Ecology \& Hydrology, Maclean Building, Crowmarsh Gifford Wallingford, Oxon, OX 10 8BB, UK \\ ${ }^{\mathrm{d}}$ Lancaster Environment Centre, Lancaster University, Lancaster LA1 4YQ UK
}

\section{A R T I C L E I N F O}

\section{Article history:}

Received 19 March 2016

Received in revised form 17 May 2016

Accepted 23 May 2016

Available online 7 June 2016

\section{Keywords:}

Ecological risk

Regional risk assessment

Ecological indicators

Coastal region

Multi-compartments pollution

Heavy metal

\begin{abstract}
A B S T R A C T
Ecological risk assessment (ERA) has been widely applied in characterizing the risk of chemicals to organisms and ecosystems. The paucity of toxicity data on local biota living in the different compartments of an ecosystem and the absence of a suitable methodology for multi-compartment spatial risk assessment at the regional scale has held back this field. The major objective of this study was to develop a methodology to quantify and distinguish the spatial distribution of risk to ecosystems at a regional scale. A framework for regional multi-compartment probabilistic ecological risk assessment (RMPERA) was constructed and corroborated using a bioassay of a local species. The risks from cadmium $(\mathrm{Cd})$ pollution in river water, river sediment, coastal water, coastal surface sediment and soil in northern Bohai Rim were examined. The results indicated that the local organisms in soil, river, coastal water, and coastal sediment were affected by $\mathrm{Cd}$. The greatest impacts from $\mathrm{Cd}$ were identified in the Tianjin and Huludao areas. The overall multi-compartment risk was $31.4 \%$ in the region. The methodology provides a new approach for regional multi-compartment ecological risk assessment.
\end{abstract}

(C) 2016 Elsevier Ltd. All rights reserved.

\section{Introduction}

Ecological risk assessment (ERA) is the process for evaluating the possibilities of adverse ecological effects occurring as a result of organism exposure to one or more environmental stressors (USEPA, 1998). This has been shown to be a good starting point in characterizing the risk of chemicals to organisms and ecosystems. The hazard quotient (HQ) approach has been widely applied to characterize the risk. It is suitable for a preliminary screening-stage risk assessment, but lacks the probabilistic paradigm inherent in risk and does not adequately account for uncertainty of environmental concentrations and species sensitivities.

The probabilistic ecological risk assessment (PERA) which allows the risk assessor to conduct estimates of uncertainty as well as stochastic properties of both exposure and response (Solomon et al., 2000), is a promising approach for evaluating the risk of dangerous chemicals. It has become increasingly important since the 1990s and has been widely applied to assess the potential adverse ecological effects of exposure to

\footnotetext{
* Corresponding author.

E-mail address: yllu@rcees.ac.cn (Y. Lu).
}

contaminated ecosystems (Brain et al., 2006; Carriger and Rand, 2008; Rand et al., 2010). However, the paucity of the toxicity data on local biota and a suitable methodology for spatial risk assessment has been the challenge for regional multi-compartment PERA.

Coastal ecosystems are considered particularly vulnerable to impacts of pollution due to the active exchange of pollutants among compartments in such regions (Cochard et al., 2008). Both different classes of organisms, such as algae or invertebrates, and the compartments in which they live can affect their sensitivity to chemicals. Thus, the same concentration of a chemical in different environmental compartments could have very different impacts.

Cadmium is recognized as presenting a high risk to ecosystems (Wang et al., 2011; Salem et al., 2014). Previous studies have indicated cadmium has played a major role in reducing species diversity and abundance, and destruction of ecosystem function, as well as being a hazard to human health (Fernandezleborans and Novillo, 1994; Moody and Green, 2010; Zhang et al., 2012). The cadmium contamination of soils, water, and sediment in Bohai Sea and nearby coastal areas and estuaries (Meng et al., 2008; Luo et al., 2010; Feng et al., 2011; Cheng et al., 2014) has been reported, however, a risk assessment for cadmium in the different environmental compartments in the region has not been carried out. The accumulation of pollutants can be greater 
in enclosed and semi-enclosed areas where the exchange of water with the open seas is limited (Karageorgis et al., 2002). Currently ecological risk assessment in Bohai Rim has been limited because of the lack of toxicity data on indigenous species (Mu et al., 2014).

The major objective of this paper was to develop a methodology to quantify and distinguish the spatial distribution of the risks throughout the different components of ecosystems within a region. A framework for regional multi-compartment probabilistic ecological risk assessment (RMPERA) was constructed based on toxicity data of local species. Assessing the risks from cadmium pollution in multiple compartments including river water, river sediment, coastal water, coastal surface sediment and soil in northern Bohai Rim was selected as a test case for the method.

\section{Framework for regional multi-compartments ecological risk assessment}

\subsection{Overview of the methodology}

A probabilistic risk approach, which compares probability distributions of actual exposure concentrations in multi-compartments (soil, river water and sediment, coastal water and sediment) with the effects data of indigenous aquatic, terrestrial and benthic species, respectively, was used to define the relationship between measures of effect and assessment endpoints. The framework is shown in Fig. 1. Compartmentspecific ecological risk in the whole region was assessed by comparing frequency distributions of exposure with toxicity thresholds derived from corresponding species sensitivity distributions (SSDs) all local to that compartment. For each compartment, different geographic locations were assessed for their vulnerability. With the support of Geographic Information System (GIS) tools, the spatial distribution of risks in the region was developed. The risk assessment results were tested with a bioassay survey in the region. The regional overall ecological risk was the sum of the weighted compartment-specific risks, with the input of weights obtained by an expert scoring method.

\subsection{Risk assessment procedure}

A 5 step procedure was developed: problem formulation, exposure assessment, effects assessment, risk characterization, and risk validation. Problem formulation identifies the stressors of concern, scoping of region and sub-region, ecosystems at risk, assessment and measurement endpoints, and expected ecological effects.

The exposure assessment phase examines probit distributions of the environmental exposures in multi- compartment (the probit or probability unit is the quantile function associated with a normal distribution). The exposure data were converted to straight line transformation of probability functions by probit transformation. The probability of the pollutants exposure was in the function of the concentration by the liner regression.

Probitof $\mathrm{con}_{i}=\mathrm{a} \operatorname{Lg}\left(\mathrm{Con}_{i}\right)+\mathrm{b}$

where $\mathrm{con}_{i}$ represents the concentration of pollutant in compartment $i$.

At the effect assessment step, the species sensitivity distributions (SSDs) of the affected species in multi-ecosystems were constructed as follows:

Probitof con $_{i}=\mathrm{a} \operatorname{Lg}\left(\right.$ toxic $\left._{i}\right)+\mathrm{b}$

where toxic $c_{i}$ represents the toxicity endpoints in compartment $i$.

At the risk characterization step, the exposure data for the different compartments in the region and sub-regions and corresponding compartment-specific SSDs were integrated into the Joint Probability Curves (JPCs) to determine the compartment-specific risk $R_{i}$ ( $i$ represents compartment $i$ ).

The overall multi-compartment risk $\left(R_{\text {multi }}\right)$ in the region was summed as follows:

$R_{\text {multi }}=\sum_{i=1}^{n} R_{i} \times W_{i}$

where $W_{i}$ was the weight of risk in compartment $i$.

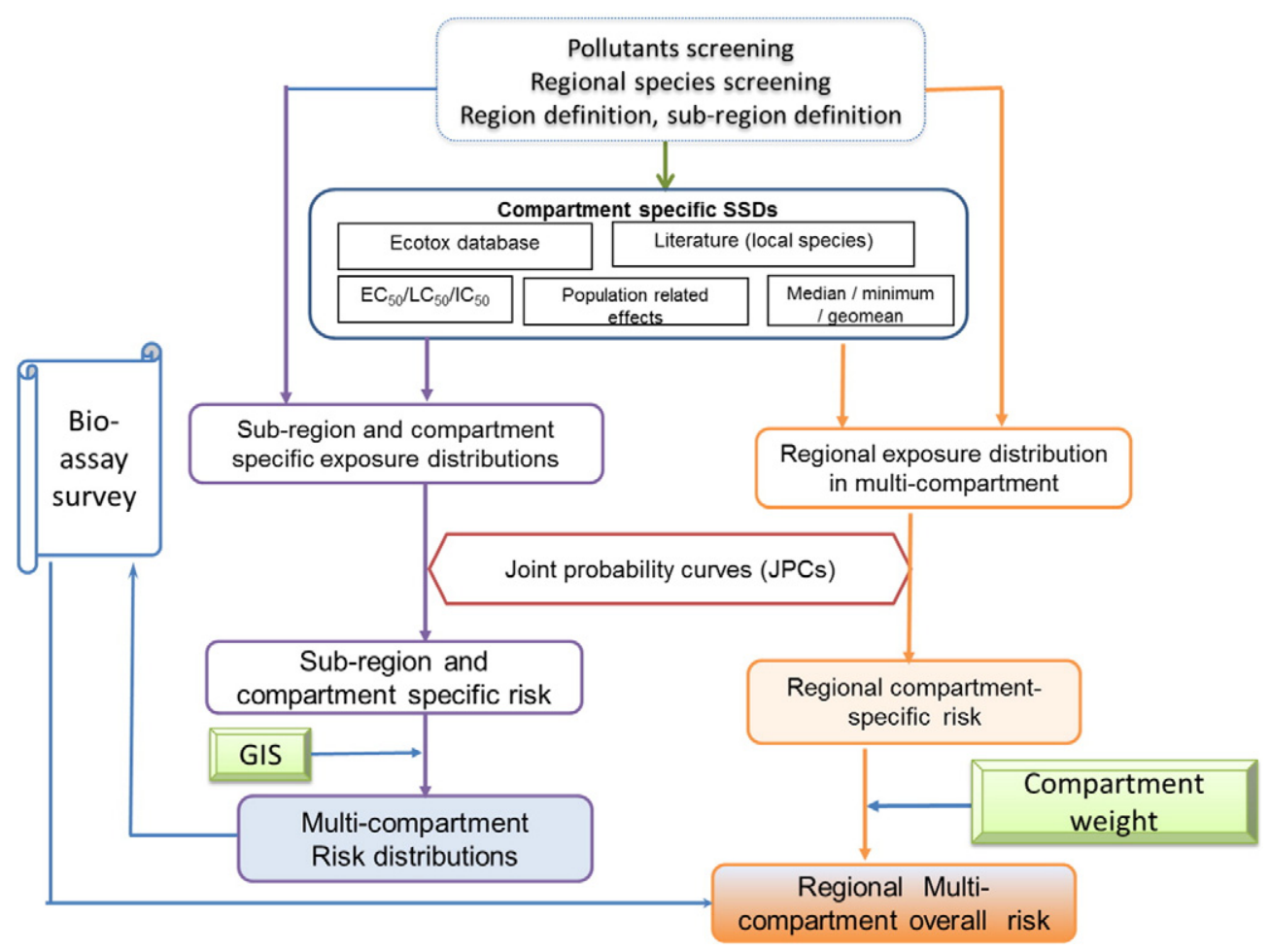

Fig. 1. Framework for regional multi-compartment probabilistic ecological risk assessment (RMPERA). 
To test the predictions a field survey on the key species and/or key ecosystem was conducted in the region. The variations of residue levels in the organisms and community structure, especially the sensitive or tolerant species which can be identified by the SSDs, were investigated.

\subsection{Key points}

The RMPERA offers a quantitative method for evaluating the risk probability for a susceptible ecosystem at specific sites and in a region by combining the compartment-specific probability distributions of exposure concentrations with the SSDs. During this process, only the biota affected directly by the chemicals is considered. The exposure estimate is based on site-specific data. The residue levels for contaminants present in sediment had to be converted to contaminant concentration in pore water since the toxicity to benthic biota is based on such data. Separate SSDs were developed for the different environmental compartments. Only plants and soil invertebrates were included in the terrestrial ecosystem because they live entirely in the soil environment.

In this case the characterization of ecological effects was based on the local species rather than on species not present in China. During the process of gathering the toxicity data, values from experiments with unacceptable designs (with interferences between the measuring

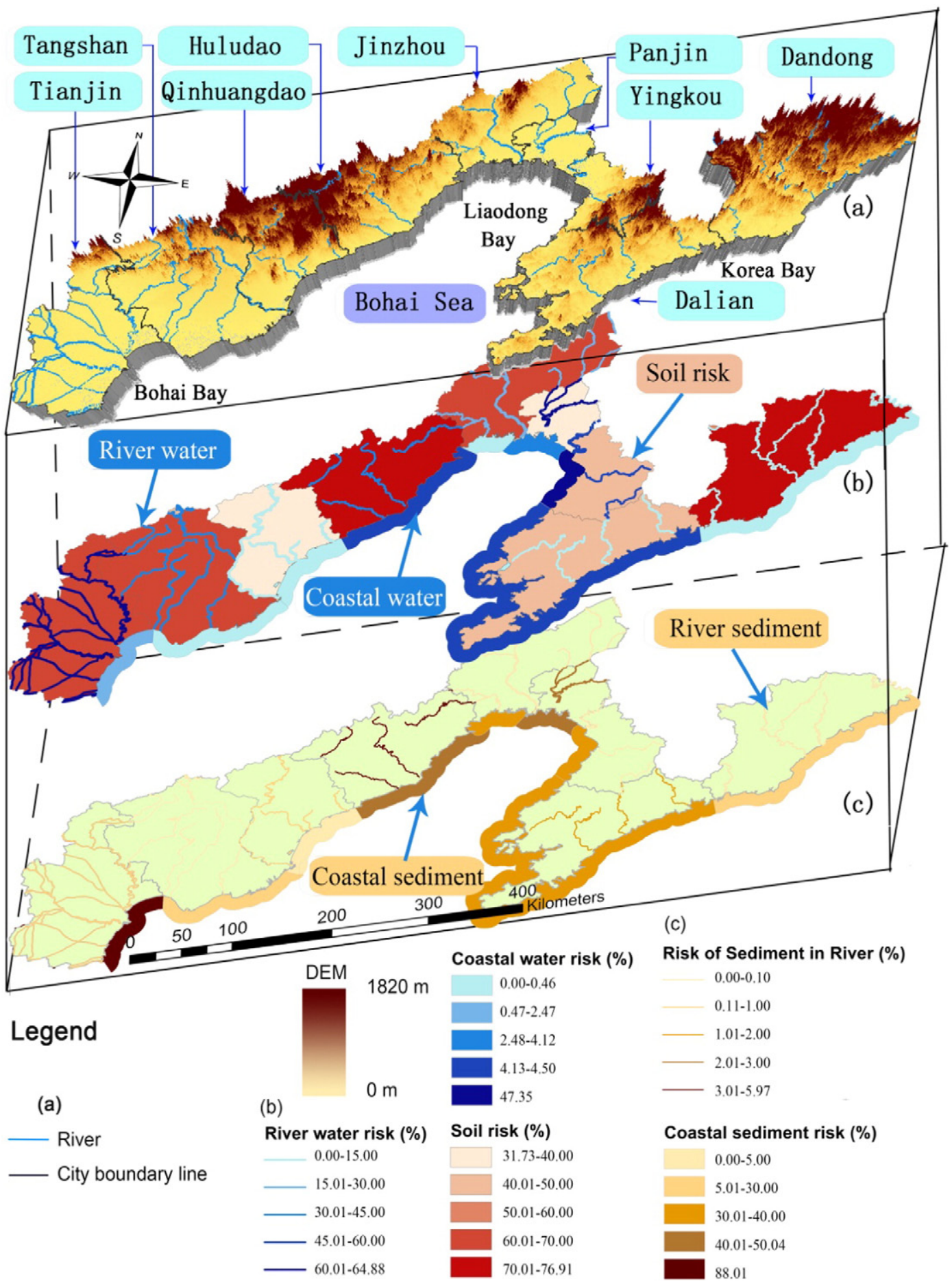

Fig. 2. Study sub-regions (a) and spatial distribution of Cadmium risks in soils, river, coastal water (b), river sediment and coastal sediment (c). 
system and test substance, or unacceptable method and insufficient documentation for assessment), or end points with a greater-than or less-than value were excluded (Klimisch et al., 1997; USEPA, 2003).

The assessment end points are defined here as clear adverse effects on wildlife populations. Only end points that could be clearly related to changes in population structure such as growth, reproduction and survival were used in the SSDs. One chemical can have an array of effects depending on the target species, the exposure timing, and the mixture in which it was delivered. It is difficult to know which end points are appropriate when assessing a chemical. The most sensitive adverse end point is not always a clear-cut choice. The criteria for the selection of assessment end points are: ecological relevance, susceptibility to the known or potential stressors, and relevance to management goals (USEPA, 1998). The occurrence of unpredictable biomarkers or delayed biomarker response (such as the xenobiotic-metabolizing enzymes and biochemical parameters involved in energy metabolism) was not included.

When data for a species with different responses were available, median lethal concentration $\left(\mathrm{LC}_{50}\right)$ and/or median effect concentrations $\left(E_{50}\right)$ were selected. No chronic SSDs were constructed because of the limited chronic toxicity data. Lowest observed (LOEC) and no observed (NOEC) effects concentration end points were excluded from the SSDs. The LOEC and NOEC can be problematic and can be criticized for lack of statistical rigour and variability at representing effects (Laskowski, 1995; Kooijman, 1996; Posthuma et al., 2002; Suter, 2007). A safety assessing factor was applied before constructing the SSDs in order to decrease the uncertainty produced by the different status between the acute single species laboratory toxicity test and the chronic multi-species exposure in natural ecosystems.

A species was only represented once in each distribution. When multiple acceptable toxicity values were available for a species, a median, minimum or geomean were calculated for use in the SSD (Schuler and Rand, 2008; Shi et al., 2014).

JPCs are widely applied PERA approaches used to assess ecological risks worldwide. In this paper, the probit transformed exposure and toxicity distribution and the extent of overlap between the two distributions were estimated by JPCs. The spatial distribution of ecological risk in the different environmental compartments in this area of China was conducted using ArcGIS.

The weight of the medium specific risk depends on the importance of the medium to the ecosystem, and the goal of risk management, which can be obtained by experts scoring method.

\section{Case study of cadmium risk in the Northern Bohai Rim}

\subsection{Target pollutants and ecosystem, scoping of region and possible source of pollutants}

The soil, river and coastal areas around the northern Bohai Sea were the focus of this study (Fig. 2a). Nine cities were identified as sub-regions for this risk assessment. The cities were: Dandong (DD), Dalian (DL), Yingkou (YK), Panjin (PJ), Jinzhou (JZ), Huludao (HLD), Qinhuangdao (QHD), Tangshan (TS) and Tianjin (TJ). The estuary and region along the coast ( $1 \mathrm{~km}$ distance from the coast) was defined as the coastal area.

The terrestrial, river aquatic and benthic, coastal aquatic and benthic ecosystems in the northern Bohai Rim and all the sub-regions were all considered in the risk assessment.

Cadmium was the target pollutant. Cadmium derived from anthropogenic activities is considered to be one of the most harmful heavy metals (along with $\mathrm{Ni}, \mathrm{Cu}, \mathrm{As}, \mathrm{Hg}$ and $\mathrm{Pb}$ ) influencing the soil environment in China according to the latest official report (MEP, 2014). The discharge of cadmium from wastewater in Liaoning Province, a major industrial area in the northern Bohai Rim, was as high as approximately $50 \mathrm{t} /$ year (ranged from 36.5 to $65.7 \mathrm{t}$ ) during 1995-2000. Although cadmium discharge decreased gradually from $31.3 \mathrm{t} /$ year in 2001 when a 15-year program called 'Bohai Blue Sea Action Plan' was launched by the Chinese government to reduce the pollution discharge to $0.02 \mathrm{t} /$ year in 2014, cadmium still posed a great burden to the local ecosystem with its continuous release along with the wastewater during the last two decades (China Statistics Press, 1995-2014).

Metal mining and processing such as lead-zinc mine exploitation, nonferrous metal smelting, electroplating and application of cadmium compound as a raw material or accelerant are considered to be the main sources. The Northern Bohai Rim is an intensively urbanized and industrialized economic zone with a wide range of cadmium sources. Tianjin is a major industrial city with gross industrial output as high as 2622 billion RMB, discharging a large volume of waste containing cadmium (Tianjin statistical bureau, 2014). Huludao city is also likely to be a very important source due to local non-ferrous metal mining, $\mathrm{Cd}$ smelting and processing.

\subsection{Exposure assessment}

Samples of soil, river water, coastal water, river sediment, and coastal sediment from 157 monitoring sites in the northern Bohai Rim were collected in 2013 and analyzed for cadmium. Soil samples were distributed evenly within the study area, the sample numbers for each city varied in terms of spatial area. River water samples were distributed along the main rivers, and at least 2 samples were collected from each river. Coastal water samples were uniformly distributed along the coastline and covered important ecosystem types along the Bohai coast. The river and coastal sediment samples were located in correspondence with water samples.

The procedure for sample collection, chemical analysis of cadmium and $\mathrm{QA} / \mathrm{QC}$ in water, sediment and soil are as same as the author's previous work and were described in Luo and Xu (Luo et al., 2007; Luo et al., 2010; Xu et al., 2013).

The examination of the cadmium concentrations in the different environmental compartments showed 3 extreme outliers and 9 mild outliers which mostly are samples from Huludao and Tianjin, indicating the higher cadmium exposure levels in those cities (Fig. 3). Concentrations of cadmium had median values of $0.26 \mathrm{mg} / \mathrm{kg}$ in soil, $0.38 \mu \mathrm{g} / \mathrm{L}$ in coastal water, $0.11 \mathrm{mg} / \mathrm{kg}$ in coastal sediment, $0.19 \mu \mathrm{g} / \mathrm{L}$ in river water, and $0.15 \mathrm{mg} / \mathrm{kg}$ in river sediment. When comparing cadmium concentrations with other compartment, river water represented a much more narrow range of values.

The cadmium concentrations in sediments were converted to the concentrations in pore water by division with Kp conversion factors which were actual measurements in water/sediment conversion of

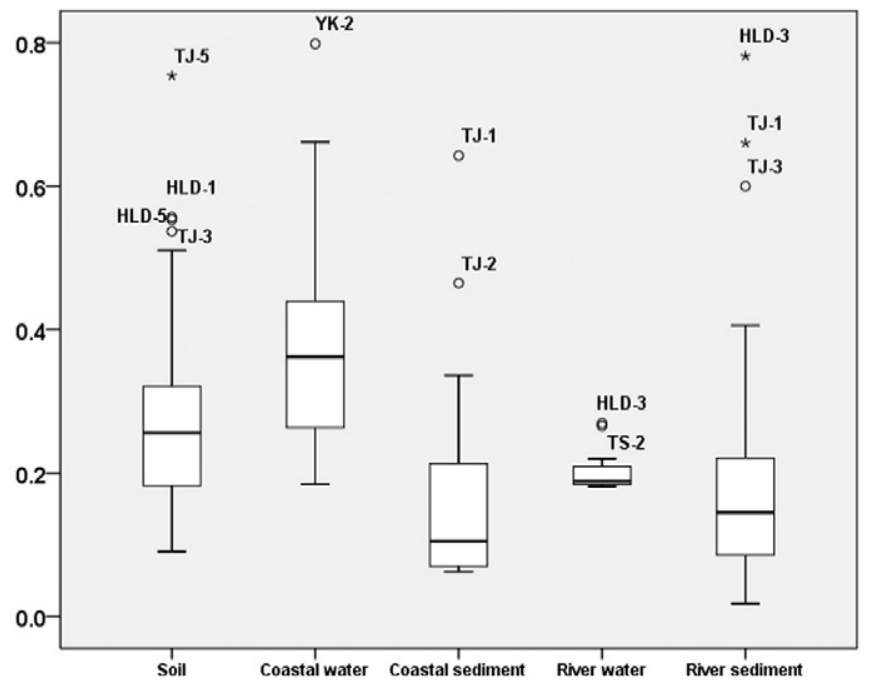

Fig. 3. Box-plot of cadmium measurement in environmental media ( $\mu \mathrm{g} / \mathrm{L}$ in water, $\mathrm{mg} / \mathrm{kg}$ in soil and sediment; ${ }^{\circ}$ refers to mild outliers, ${ }^{*}$ refers to extreme outliers). 
Table 1

The regression parameters and 95\% percentile value of cadmium exposure in northern Bohai rim.

\begin{tabular}{lrrll}
\hline Environmental compartments & Slope & Intercept & R Square & 95\% percentile \\
\hline Soil & 4.828 & 7.902 & 0.987 & 0.549 \\
River water & 15.705 & 16.050 & 0.847 & 0.252 \\
River sediment & 2.176 & 8.883 & 0.970 & 0.094 \\
Coastal water & 4.804 & 7.215 & 0.940 & 0.761 \\
Coastal sediment & 2.659 & 9.480 & 0.900 & 0.086 \\
\hline
\end{tabular}

a Unit: $\mathrm{mg} / \mathrm{kg}$ in soil, $\mu \mathrm{g} / \mathrm{L}$ in other compartments.

river and sea in northern Bohai Sea area (8.94 for river sediment and 6.4 for coastal sediment (Fan, 1999; Qin et al., 2013) for risk characterization. The distribution regression parameters and the corresponding 95\% values estimated by the regression of the exposure distribution (probit of exposure $=\operatorname{Lg}(\mathrm{Con})+\mathrm{b}$ ) for each compartment are

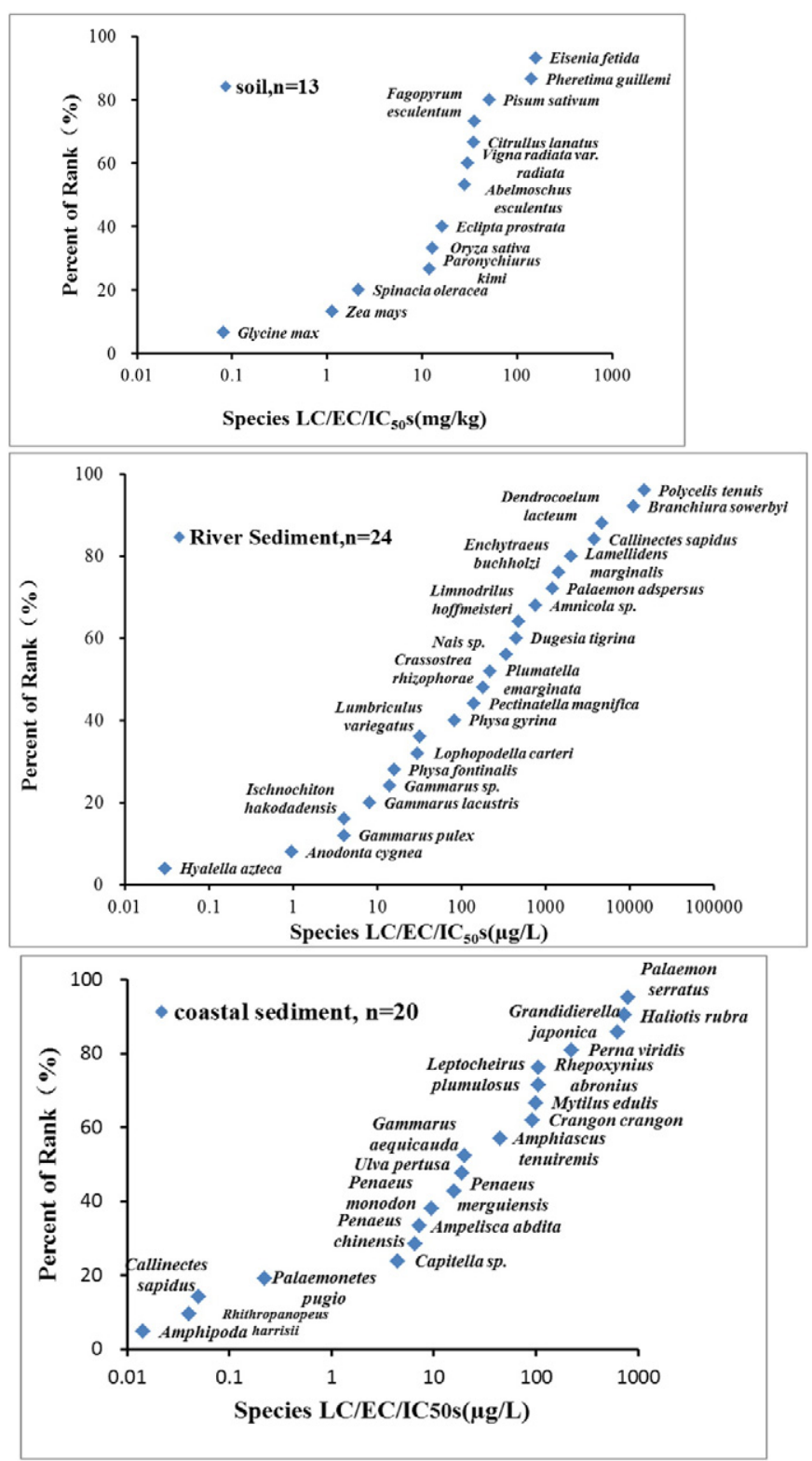

Fig. 4. SSDs for cadmium in soil, river water, river sediment, coastal water, and coastal sediment $\left(\mathrm{EC}_{50} / \mathrm{LC}_{50} / \mathrm{IC}_{50}\right.$ values were divided by a safety assessing factor of 5 ). presented in Table 1. The linear regressions for all the environmental compartments were satisfactory with reasonable R square values. The results showed that cadmium exposure was greatest in coastal water, followed by soil and river water, very low in both the river sediment and coastal sediment.

\subsection{Effects assessment}

Toxicity data for local species were developed from a toxicity databank collected from the literature and the US EPA AQUIRE database. All laboratory toxicity data related to species growth, survival and population growth were considered as the measurement end points. Most of the $\mathrm{EC}_{50} / \mathrm{LC}_{50} / \mathrm{IC}_{50}$ data were obtained directly from the literature and database. $\mathrm{EC}_{50} / \mathrm{LC}_{50} / \mathrm{IC}_{50}$ for some terrestrial species were regressed based on the results in literature since the authors presented the effects only but without the regression value. Where more than one toxicity value was available for a single species, the minimum value was selected. The SSDs for cadmium in soil, river water, river sediment, coastal water, and coastal sediment (Fig. 4) were constructed with $\mathrm{EC}_{50} / \mathrm{LC}_{50} /$ $\mathrm{IC}_{50}$ values which were divided by a safety assessing factor (the factor is equal to 5 in this case (Kenaga, 1982; Maltby et al., 2005) to determine the sensitivity of terrestrial, river aquatic and benthic, coastal aquatic and benthic organisms.

The SSDs were converted to straight line probability functions by probit transformation. Using linear regression, the probit of toxicity is equals to a $\operatorname{Lg}\left(\mathrm{EC}_{50}\right)+\mathrm{b}$. The regression parameters and the 5 th percentile concentration of effects from the cumulative frequency distribution in each of the environmental compartments are shown in Table 2.The linear regressions for river water, river sediment, coastal water and coastal sediment were satisfactory with reasonable $\mathrm{R}$ square value, while the value for soil was lower but still acceptable.

\subsection{Risk characterization}

The JPC method of integrating the exposure and effects distributions in the common axis was used to determine the likelihood of adverse ecological effects (Hunt et al., 2010). The specific assessment end point was designed to ensure the protection of at least $95 \%$ of aquatic, terrestrial and benthic species $\left(\mathrm{HC}_{5}\right)$. The probability that the $5 \%$ effect threshold could be exceeded at any time can then be determined. The compartment-specific sub-regional exposure distributions were integrated with the corresponding compartment SSDs, to define the sub-regional and compartment specific risks. The spatial risk distribution in each compartment was presented using ArcGIS version 9.3. The regional overall risk was the sum of the environmental compartment-specific weight multiplied by the environmental compartment-specific risk which was defined by the JPC of regional exposure and the SSD.

\subsubsection{Spatial distribution of cadmium risk in the different environmental compartments}

The spatial distribution of cadmium risk to the terrestrial ecosystem (Fig. 2b) showed that cadmium posed the greatest risk in the cities along the Liaodong Bay (Huludao and Jinzhou), Bohai Bay (Tianjin and Tangshan) and Korea Bay (Dandong), while risks in all the other areas were low.

The spatial distribution of cadmium risk in coastal sediment (Fig. 2c) was similar to that in the terrestrial ecosystem. Tianjin showed the greatest risk, followed by Huludao, Panjin and Jinzhou, while Tangshan and Qinhuangdao had much lower Cd risk. Due to the history of heavy industrial development in these cities, cadmium accumulation is relatively severe, and the risk posed by cadmium is of concern.

The distribution of cadmium risk in coastal water (Fig. 2b) exhibited a different trend, where Yingkou, Huludao, Panjin and Dalian, located in the Liaodong Bay, presented high risks, while all the other coastal city regions showed negligible risks. 

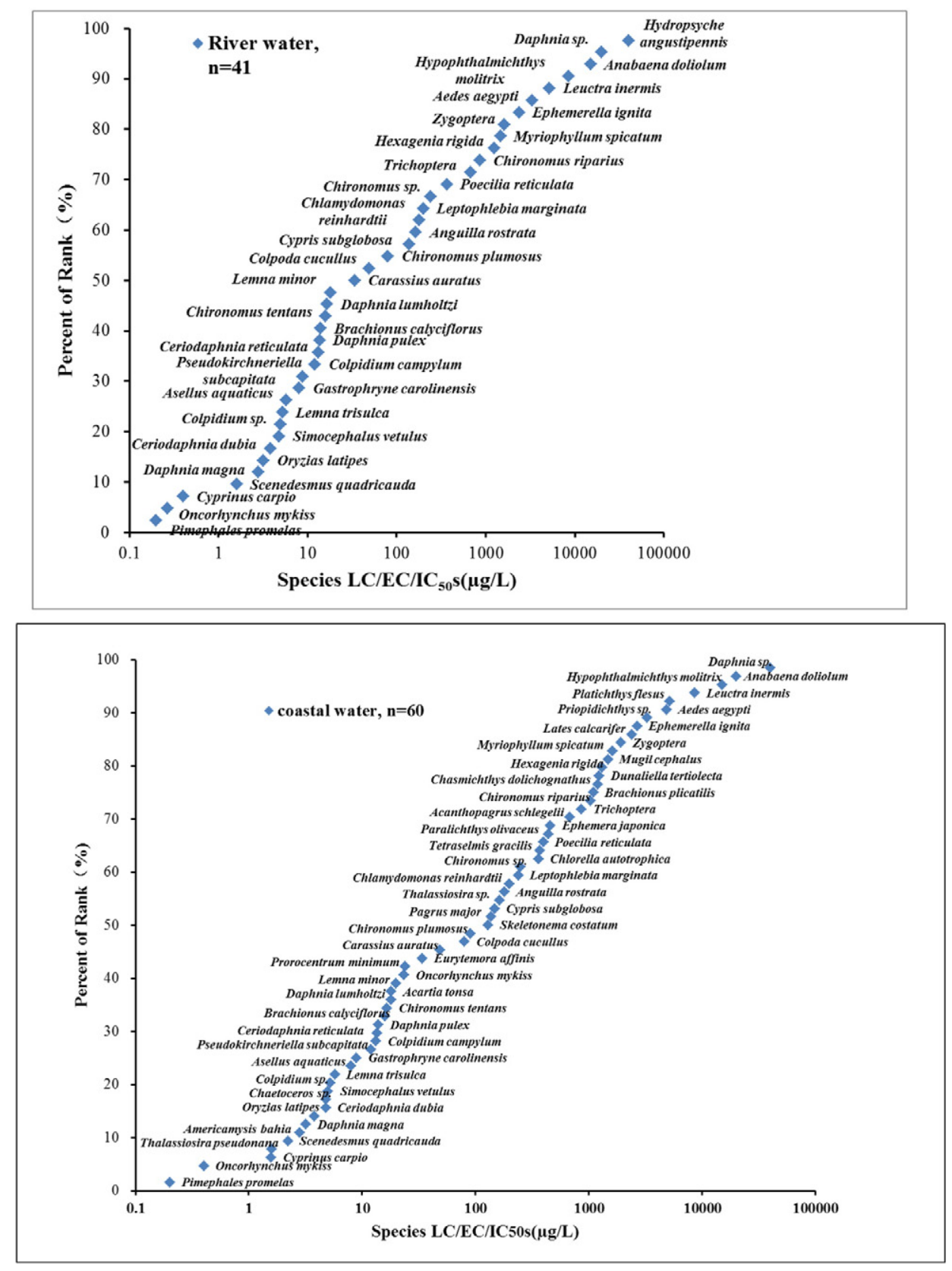

Fig. 4 (continued).

The risks from cadmium in local river water (Fig. 2b) were ranked in the order of Tianjin, Panjin, Yingkou, Huludao, Tangshan and Jinzhou. These surface waters with high Cd risk were in similar locations to soil high risk areas, which suggested common local sources of unregulated discharge of industrial waste were important sources.

Table 2

The regression parameters and 95\% percentile value of SSDs.

\begin{tabular}{lllll}
\hline Environmental compartments & Slope & Intercept & R Square & 95\% percentile \\
\hline Soil & 0.911 & 3.954 & 0.846 & 0.220 \\
River water & 0.668 & 3.782 & 0.978 & 0.230 \\
River sediment & 0.642 & 3.654 & 0.960 & 0.341 \\
Coastal water & 0.745 & 3.545 & 0.987 & 0.555 \\
Coastal sediment & 0.598 & 4.329 & 0.913 & 0.024 \\
\hline
\end{tabular}

a Unit: $\mathrm{mg} / \mathrm{kg}$ in soil, $\mu \mathrm{g} / \mathrm{L}$ in other compartments.

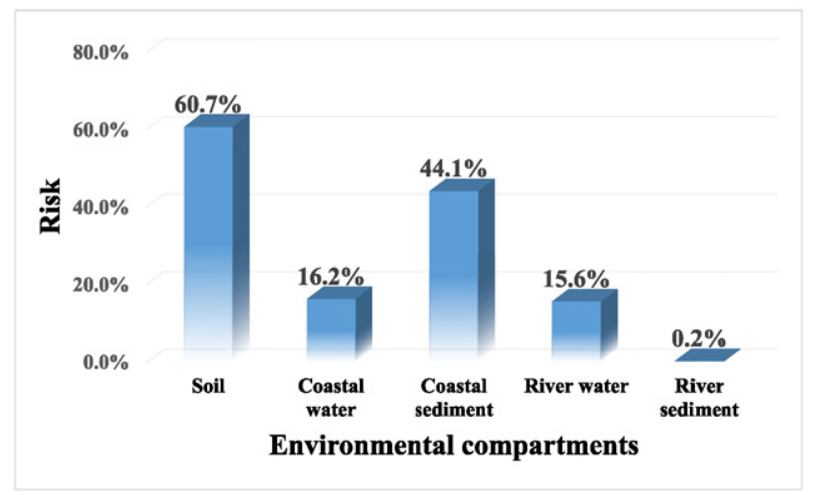

Fig. 5. Risk characterization of cadmium in specified environmental medium in Northern Bohai Rim. 
Table 3

AHP weight matrix.

\begin{tabular}{llllll}
\hline & Soil & $\begin{array}{l}\text { River } \\
\text { water }\end{array}$ & $\begin{array}{l}\text { River } \\
\text { sediment }\end{array}$ & $\begin{array}{l}\text { Coastal } \\
\text { water }\end{array}$ & $\begin{array}{l}\text { Coastal } \\
\text { sediment }\end{array}$ \\
\hline Soil & 1 & 2 & 1 & 2 & 0.5 \\
River water & 0.5 & 1 & 0.33 & 0.5 & 0.33 \\
River sediment & 1 & 3 & 1 & 3 & 0.5 \\
Coastal water & 0.5 & 2 & 0.33 & 1 & 0.33 \\
Coastal sediment & 2 & 3 & 2 & 3 & 1 \\
\hline
\end{tabular}

The risks from cadmium in river sediment across all sub-regions were rather low, except for the Huludao rivers, followed by Panjin rivers, while negligible risk was shown in all the river areas (Fig. 2c).

Thus, overall the Tianjin Region was distinguished by high risk to soil, river and coastal sediment organisms from $\mathrm{Cd}$. This was followed by the Huludao region which also revealed high risk to similar communities. Interestingly, Qinhuangdao Region, almost midway between Tianjin and Huludao had much lower risks. The local nature of coastal sediment and water Cd risks is noteworthy. The Bohai Sea is composed of Liaodong Bay (in the north), Bohai Bay (in the west), Laizhou Bay (in the south) and the Central Area. Liaodong Bay is the largest bay of the Bohai Sea, it takes 15 years to complete a water exchange cycle (Wan et al., 2008). Both Bohai Bay and Liaodong Bay are surrounded by highly industrialized areas. The water residence time is quite long in both Bohai Bay (599 d) and Liaodong Bay (502 d) due to their semi-enclosed geographical condition, much longer than that in other areas of the Bohai Sea, though it is as long as $319 \mathrm{~d}$ and $338 \mathrm{~d}$ in Laizhou Bay and Center area, respectively (Cai, 2013). This indicates both the relative immobility of $\mathrm{Cd}$ and the lack of water and sediment mixing in the two bays.

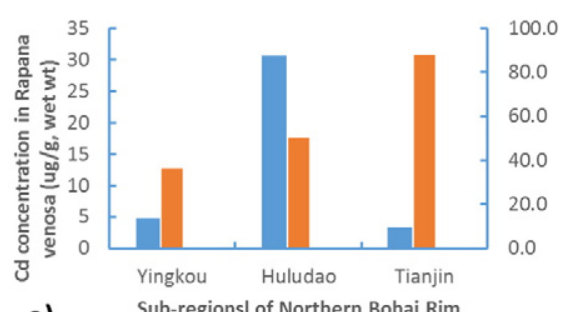

a) Sub-regionsl of Northern Bohai Rim

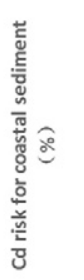
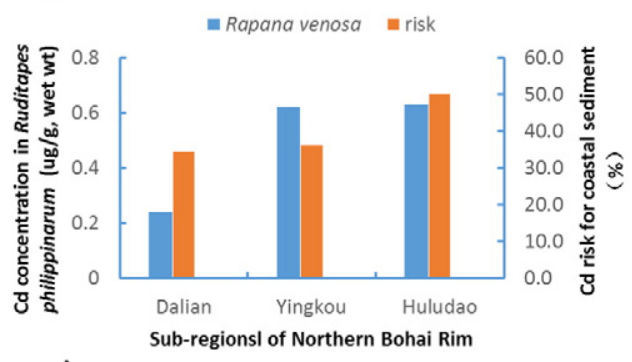

c)
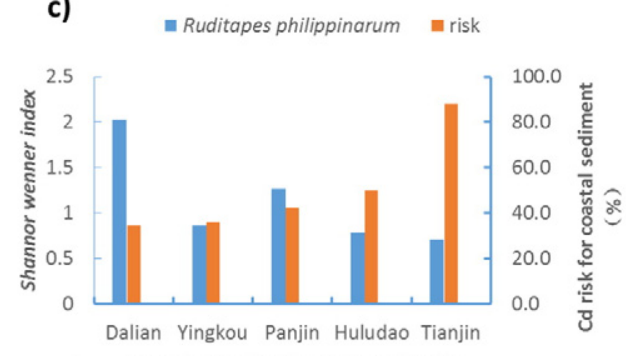

e) sub-regions of the Northern Bohai Rim

m Shannor wenner index $=$ Cd risk for coastal sediment
Cadmium risk in this region is directly related to industry discharge. Cadmium poses great risk in the region of Huludao in all the environmental compartments, the high risk of cadmium mainly comes from its lead-zinc industry. Huludao is a large production base of lead-zinc in northeast China, with the longest history of lead-zinc mining and zinc production in China, with zinc production reaching 253,000 tons in 2013. The main sources of cadmium risk in Tianjin are attributable to the pillar industries closely related to electroplating including aeronautics and astronautics, electronic components, and equipment manufacturing, with increasing production in recent years as a result of the rapid development of the industry park in Tianjin harbor.

\subsubsection{Regional risk characterization}

The relative risk from cadmium to the different environmental compartments across the whole region showed that soil organisms were most at risk (Fig. 5). Risks were also high for wildlife in coastal sediment, with similar but lower risks for river and coastal water while for river sediment organisms seemed to be the least at risk.

The weighting given to each environmental compartment was related to the importance of the ecosystem in the region. In this case, AHP (analytical hierarchical process) matrix (Table 3) was applied to get the multiple compartment risk weights according to experts scoring (1-3) and effects assessment. Scoring was given based on the resistance and resilience of Cadmium risks on each ecosystem. The following weightings of $0.20,0.09,0.24,0.12$ and 0.36 were obtained for soil, river water, river sediment, coastal water and coastal sediment, respectively Therefore the risk of cadmium in this case to the overall environment in the region was $31.4 \%$.

Cadmium exposure was the greatest in coastal water, followed by soil, river water, river sediment and coastal sediment (Table 1 and Fig. 3). In

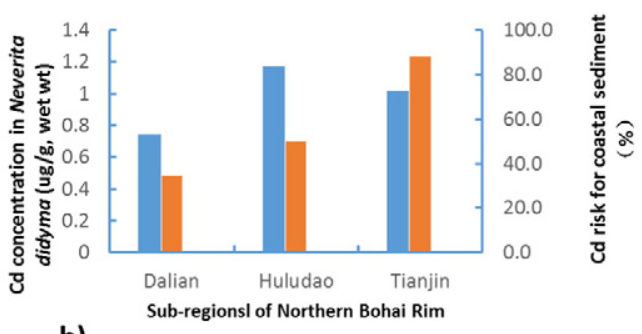

b)
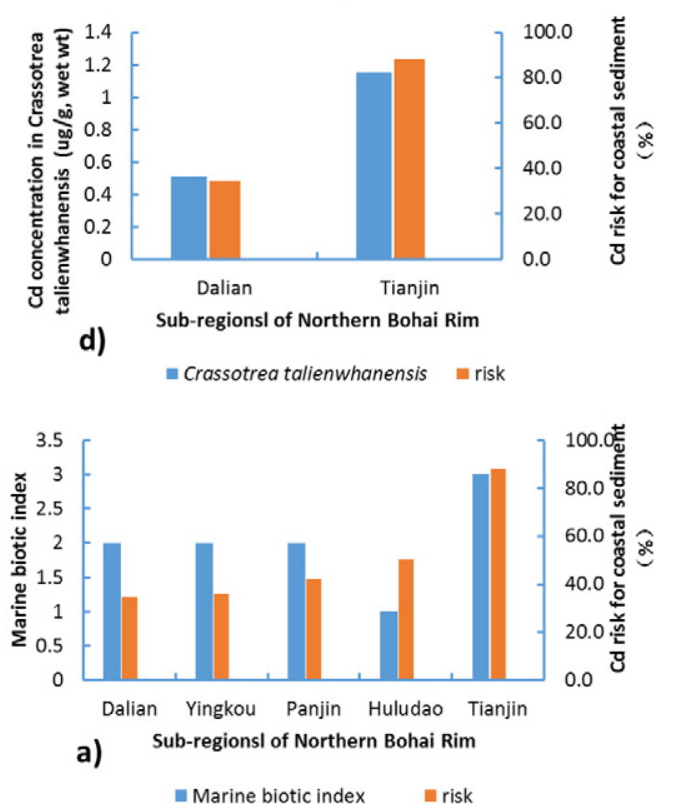

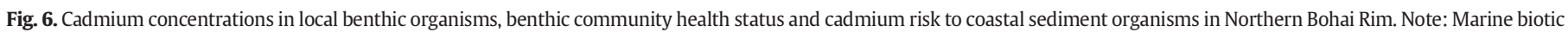
index is a qualitative index, we define " 1 = Good-moderate, 2 = Good, 3 = Excellent-good" (Panel f). 
this analysis, cadmium posed the greatest risk to soil organisms (60.8\%) followed by coastal sediment (44.1\%), moderate risk in coastal water (16.2\%) and river water (15.6\%), while risks to organisms in river sediment were the lowest. The most sensitive organisms to cadmium were in coastal sediment (Table 2), followed by those in soil, river water, river sediment and coastal water. Cadmium showed high risk to benthic organisms in coastal sediment (ranked 2) due to its high sensitivity, although the exposure was the lowest. The exposure risk of cadmium in coastal water was ranked first, while the risk to aquatic organisms in coastal water was ranked 3rd due to lowest sensitivity to cadmium. Soil presented greatest risk due to both high exposure and terrestrial sensitivity (both were ranked 2nd).

\subsection{Corroborating the risk analysis with field data}

Data on the bioaccumulation of cadmium in local benthic organisms and benthic community in the coastal sediment of the Northern Bohai Rim were collected (Liang et al., 2004; Cai et al., 2012) and compared against the results from the risk analysis (Fig. 6).

Cadmium was found to have accumulated in all of the organisms examined, especially in Rapana venosa, in Huludao. The community biodiversity index and health index also showed that surface sediment in Huludao, Tianjin and Yingkou were in poor ecological health status. It will be recalled that these regions were identified as having particularly high risks to their coastal sediment organisms (Fig. 2c). A positive correlation between the risk value and cadmium concentrations (Fig. 6a, b, c and d), and a negative correlation between the risk value and community health index (Fig. 6e and f), were observed. This comparison of predicted Cd risks using the risk assessment protocol and actual field observations is encouraging.

\section{Conclusion and perspective}

This study has demonstrated that it is possible to utilize field measurements of a pollutant present in different local terrestrial and marine compartments to generate an overall ecosystem risk for different geographic regions. The approach was focused in this case on China, as only local wildlife ecotoxicity data was used to assess the vulnerability of an ecosystem, but could also be used in other parts of the world. Cadmium in the Northern Bohai coastal region was examined as a test case for this risk assessment approach. The method highlighted that risks could vary dramatically depending on the environmental compartment and by region. For example, soil organisms were generally more at risk than river sediments and regions only $50 \mathrm{~km}$ apart could be facing very different threat levels. The highest environmental risks from cadmium were in Tianjin and Huludao. As a test case it was found that coastal sediment organisms had the highest $\mathrm{Cd}$ related impacts in the regions predicted to be high risk.

The methodology presented in this study is flexible and adaptable in terms of temporal scales. The temporal distribution and prediction of the regional ecological risks could be defined by replacing the input of actual exposure data with the historical data or future data through scenario analysis.

\section{Acknowledgements}

The authors are grateful for the support provided by the National Natural Science Foundation of China (grant no. 41272487; no. 414201040045), the International S\&T Cooperation Program of China (grant no. 2012DFA91150), and the Key Research Program of the Chinese Academy of Sciences (grant no. KZZD-EW-TZ-12). A. Johnson is grateful to CEH science budget provided by NERC which has supported his collaboration.

\section{References}

Brain, R.A., Sanderson, H., Sibley, P.K., Solomon, K.R., 2006. Probabilistic ecological hazard assessment: evaluating pharmaceutical effects on aquatic higher plants as an example. Ecotoxicol. Environ. Saf. 64, 128-135.

Cai, Z., 2013. Modelling Average Residence Time of the Waterbody in Bohai and its Seasonal Variation [Master]: Ocean University of China.

Cai, W.-q., Liu, L.-S., Qiao, F., Lin, K.-X., Zhou, J., 2012. Study on the changes of macrobenthos communities and their causes in Bohai Bay. Huanjing Kexue 33, 3104-3109.

Carriger, J., Rand, G., 2008. Aquatic risk assessment of pesticides in surface waters in and adjacent to the Everglades and Biscayne National Parks: I. Hazard assessment and problem formulation. Ecotoxicology 17, 660-679.

Cheng, H., Li, M., Zhao, C., Li, K., Peng, M., Qin, A., Cheng, X., 2014. Overview of trace metals in the urban soil of 31 metropolises in China. J. Geochem. Explor. 139, 31-52.

China Statistics Press, 1995, 1996, 1997, 1998, 1999, 2000, 2001, 2002, 2003, 2004, 2005 2006, 2007, 2008, 2009,2010,2011,2012,2013, 2014,. China Statistical Yearbook on Environment.

Cochard, R., Ranamukhaarachchi, S.L., Shivakoti, G.P., Shipin, O.V., Edwards, P.J., Seeland, K.T., 2008. The 2004 tsunami in Aceh and Southern Thailand: a review on coastal ecosystems, wave hazards and vulnerability. Perspectives in Plant Ecology, Evolution and Systematics. 10 , pp. 3-40.

Fan, Z., 1999. Study on definition of marine sediment criteria by Equilibrium Partitioning method. Environmental Protection in Transportation 20, 21-25.

Feng, H., Jiang, H., Gao, W., Weinstein, M.P., Zhang, Q., Zhang, W., Yu, L., Yuan, D., Tao, J. 2011. Metal contamination in sediments of the western Bohai Bay and adjacent estuaries, China. J. Environ. Manag. 92, 1185-1197.

Fernandezleborans, G., Novillo, A., 1994. Experimental approach to cadmium effects on a marine protozoa community. Acta Hydrochim. Hydrobiol. 22, 19-27.

Hunt, J., Birch, G., Warne, M.S.J., 2010. Site-specific probabilistic ecological risk assessment of a volatile chlorinated hydrocarbon-contaminated tidal estuary. Environ. Toxicol. Chem. 29, 1172-1181.

Karageorgis, A.P., Sioulas, A.I., Anagnostou, C.L., 2002. Use of surface sediments in Pagassitikos Gulf, Greece, to detect anthropogenic influence. Geo-Mar. Lett. 21, 200-211.

Kenaga, E.E., 1982. Predictability chronic toxicity from acute toxicity of chemicals in fish and aquatic invertebrates. Environ. Toxicol. Chem. 1, 347-358.

Klimisch, H.J., Andreae, M., Tillmann, U., 1997. A systematic approach for evaluating the quality of experimental toxicological and ecotoxicological data. Regul. Toxicol Pharmacol. 25, 1-5.

Kooijman, S., 1996. An alternative for NOEC exists, but the standard model has to be abandoned first. Oikos 75, 310-316.

Laskowski, R., 1995. Some good reasons to ban the use of NOEC, LOEC and related concepts in ecotoxicology. Oikos 73, 140-144.

Liang, L.N., He, B., Jiang, G.B., Chen, D.Y., Yao, Z.W., 2004. Evaluation of mollusks as biomonitors to investigate heavy metal contaminations along the Chinese Bohai Sea. Sci. Total Environ. 324, 105-113.

Luo, W., Lu, Y., Giesy, J.P., Wang, T., Shi, Y., Wang, G., Xing, Y., 2007. Effects of land use on concentrations of metals in surface soils and ecological risk around Guanting Reservoir, China. Environ. Geochem. Health 29, 459-471.

Luo, W., Lu, Y., Wang, T., Hu, W., Jiao, W., Naile, J.E., Khim, J.S., Giesy, J.P., 2010. Ecological risk assessment of arsenic and metals in sediments of coastal areas of northern Bohai and Yellow Seas, China. Ambio 39, 367-375.

Maltby, L., Blake, N., Brock, T.C.M., Van den Brink, P.J., 2005. Insecticide species sensitivity distributions: importance of test species selection and relevance to aquatic ecosystems. Environ. Toxicol. Chem. 24, 379-388.

Meng, W., Qin, Y., Zheng, B., Zhang, L., 2008. Heavy metal pollution in Tianjin Bohai Bay, China. J. Environ. Sci. 20, 814-819.

MEP, 2014. Nationwide Soil Pollution Survey Report. Ministry of Environment Protection and Ministry of Land Resources, The People's Republic of China.

Moody, C., Green, I.D., 2010. Assimilation of Cd and Cu by the carnivorous plant Sarracenia leucophylla Raf. fed contaminated prey. Environ. Sci. Technol. 44, 1610-1616.

Mu, J., Wang, J., Wang, Y., Cong, Y., Zhang, Z., 2014. Probabilistic ecological risk assessment of cadmium in the Bohai Sea using native saltwater species. Acta Oceanol. Sin. 33 212-221.

Posthuma, L., Traas, T.P., de Zwart, D., Suter II, G.W., 2002. Conceptual and technical outlook on species sensitivity distributions. In: Posthuma, L., Suter II, G.W., Traas, T.P. (Eds.), Species Sensitivity Distributions in Ecotoxicology. Lewis publishers, Boca Raton, pp. 475-508.

Qin, N., He, W., Kong, X.-Z., Liu, W.-X., He, Q.-S., Yang, B., Ouyang, H.-L., Wang, Q.-M., Xu, F.-L., 2013. Ecological risk assessment of polycyclic aromatic hydrocarbons (PAHs) in the water from a large Chinese lake based on multiple indicators. Ecol. Indic. 24, 599-608.

Rand, G., Carriger, J., Gardinali, P., Castro, J., 2010. Endosulfan and its metabolite, endosulfan sulfate, in freshwater ecosystems of South Florida: a probabilistic aquatic ecological risk assessment. Ecotoxicology 19, 879-900.

Salem, D.M.S.A., Khaled, A., El Nemr, A., El-Sikaily, A., 2014. Comprehensive risk assessment of heavy metals in surface sediments along the Egyptian Red Sea coast. Egypt J. Aquat. Res. 40, 349-362.

Schuler, L., Rand, G., 2008. Aquatic risk assessment of herbicides in freshwater ecosystems of South Florida. Arch. Environ. Contam. Toxicol. 54, 571-583.

Shi, Y., Burns, M., Ritchie, R.J., Crossan, A., Kennedy, I.R., 2014. Probabilistic risk assessment of diuron and prometryn in the Gwydir River catchment, Australia, with the input of a novel bioassay based on algal growth. Ecotoxicol. Environ. Saf. 106, 213-219.

Solomon, K., Giesy, J., Jones, P., 2000. Probabilistic risk assessment of agrochemicals in the environment. Crop. Prot. 19, 649-655. 
Suter II, G.W., 2007. Ecological Risk Assessment. CRC Press, Boca Raton, Fl.

Tianjin Statistical Bureau, 2014. Tianjin Statistical Yearbook.

USEPA, 1998. Guidelines for Ecological Risk Assessment. U.S. Environmental Protection Agency, Washington, DC

USEPA, 2003. Guidelines for Developing Ecological Soil Screening Levels. U.S. Environmental Protection Agency, Washington, DC.

Wan, L., Wang, N.B., Li, Q.B., Zhou, Z.C., Sun, B., Xue, K., et al., 2008. Estival distribution of dissolved metal concentrations in Liaodong Bay. Bull. Environ. Contam. Toxicol. 80 (4), 311-314.
Wang, Y., Yang, Z., Shen, Z., Tang, Z., Niu, J., Gao, F., 2011. Assessment of heavy metals in sediments from a typical catchment of the Yangtze River, China. Environ. Monit. Assess. 172, 407-417.

Xu, L., Wang, T., Ni, K., Liu, S., Wang, P., Xie, S., Meng, J., Zheng, X., Lu, Y., 2013. Metals contamination along the watershed and estuarine areas of southern Bohai Sea, China. Mar. Pollut. Bull. 74, 453-463.

Zhang, X., Yang, L., Li, Y., Li, H., Wang, W., Ye, B., 2012. Impacts of lead/zinc mining and smelting on the environment and human health in China. Environ. Monit. Assess. $184,2261-2273$. 